\title{
Czy napromienianie części piersi powinno się stać standardowym elementem oszczędzającego leczenia chorych na wczesnego raka piersi? Głos na tak
}

\author{
Dawid Murawa
}

\author{
Is accelerated partial breast irradiation (APBI) the standard? Vote for YES
}

\section{$\mathrm{BCT}$ - problem radioterapii}

Procedurą z wyboru w leczeniu wczesnego raka piersi jest postępowanie oszczędzające gruczoł piersiowy - tzw. BCT (Breast Conservative Treatment). Jak dobrze wiemy, klasyczne postępowanie obejmuje usunięcie guza pierwotnego z marginesem zdrowej tkanki ( różne mianownictwo: lumpektomia, kwadrantektomia, częściowa mastektomia, szerokie wycięcie guza) oraz następowe napromienianie całego gruczołu piersiowego do dawki 45-50 Gy. U większości chorych dodatkowo wykonuje się tzw. boost, czyli dopromienienie loży po usuniętym guzie w dawce 10-16 Gy. Liczne badania udowodniły, iż powyższe postępowanie gwarantuje wyniki w zakresie zarówno przeżyć, jak i kontroli miejscowej na poziomie porównywalnym z zabiegiem usunięcia gruczołu piersiowego [1-3].

W licznych badaniach oceniano znaczenie uzupełniającej radioterapii w chirurgicznym leczeniu oszczędzającym chorych na raka gruczołu piersiowego. Badania udowodniły, iż zmniejszenie ryzyka wznowy miejscowej jest znaczne. Metaanaliza Clarke'a prezentuje grupę 42000 chorych leczonych z powodu raka piersi różnymi technikami. BCT wykonano w grupie 7300 chorych. Radioterapię na cały gruczoł podawano do dawki 50 Gy. Ryzyko wznowy miejscowej w okresie 5 lat w grupie z radioterapią wyniosło $7 \%$ vs $26 \%$ przy braku napromieniania [4]. Kolejny etap naszej wiedzy to idea podania dodatkowej dawki na lożę po usuniętym guzie. W badaniu EORTC 22881-10882 grupa 559 chorych na raka piersi leczonych z oszczędzeniem gruczołu piersiowego została podzielona na dwie grupy. Tylko jedna z nich otrzymała boost na lożę po usuniętym guzie w dawce $16 \mathrm{~Gy}$. W obu grupach podano dawkę 50 Gy na całą pierś. Badanie wskazało jednoznacznie na zmniejszenie ryzyka wznowy miejscowej w grupie otrzymującej dodatkową dawkę na lożę. Spadek dotyczył wszystkich grup wiekowych, ale najwyraźniejszy był u chorych w młodszym wieku [5, 6].

Zatem powyższy udowodniony standard postępowania gwarantuje - można powiedzieć - doskonałe wyniki leczenia chorych na wczesnego raka piersi, u których zachowujemy gruczoł piersiowy. Zatem gdzie tkwi problem w tego typu postępowaniu?

Po pierwsze, mimo niezaprzeczalnych korzyści płynących z BCT wykorzystanie tej techniki pozostaje problemem. Według różnych doniesień procent kobiet kwalifikujących się do BCT leczonych tą techniką waha się w różnych krajach w szerokim zakresie od $10 \%$ do $80 \%$. Dodatkowo okazuje się, że od $15 \%$ do $30 \%$ chorych przechodzących kwadrantektomię z powodu raka nie otrzymuje pooperacyjnej radioterapii [7]. Dlaczego? Przede wszystkim proces leczenia radioterapeutycznego po chirurgii zgodnie z tym, co przedstawiono powyżej to dodatkowe 6-7 tygodni. I tutaj pojawiają się problemy związane $z$ dogodnością, dostępem i kosztami takiego postępowania. Często rzeczywiste ograniczenie dotyczy takich kwestii logistycznych, jak: odległość od miejsca zamieszkania do zakładu radioterapii, brak transportu, brak odpowiedniego wsparcia socjalnego, problemy medycyny ambulatoryjnej - niższy status pacjenta poradnianego. Inny problem, dyskutowany nawet w takich krajach jak Stany Zjednoczone, to fakt, iż chore po kwadrantektomii stanowią

I Oddział Chirurgii Onkologicznej i Ogólnej

Wielkopolskie Centrum Onkologii w Poznaniu

Wystąpienie podczas I Konferencji Naukowej czasopisma Nowotwory „Debaty onkologiczne” 5-6 kwietnia 2013 roku 
do $30 \%$ pacjentów w zakładach radioterapii. Blokuje to zatem szeroki dostęp innych grup chorych do tej dziedziny medycyny. Większość krajów na świecie boryka się z problemem liczby aparatów do radioterapii, na przykład w Hiszpanii ilość tych urządzeń w 2004 roku wynosiła 177. Potrzeby tego kraju kształtują się natomiast na poziomie 266-316 [7].

Po drugie, na podstawie licznych dostępnych badań można stwierdzić, iż obecny sposób postępowania z napromienianiem całego gruczołu piersiowego jest kwestionowany. Jak duża jest tutaj grupa tzw. overtreatment?

Czy można na obecnym etapie wiedzy zaproponować takie techniki, które poprawiłyby dostęp do tej metody leczenia chorych na raka gruczołu piersiowego, jaką jest BCT? Wydaje się, iż taką techniką jest APBI (Accelerated Partial Breast Irradiation)!

\section{APBI - wytyczne ASTRO i GEC-ESTRO}

W 2010 roku kolejno najpierw ASTRO (American Society for Radiation Oncology), a następnie GEC-ESTRO (Groupe Européen de Curiethérapie - European Society for Therapeutic Radiology and Oncology) zaproponowały wytyczne, na bazie których można stosować APBI w określonych grupach chorych poza badaniami klinicznymi [8-10]. Była to odpowiedź na dane mówiące, iż ponad 30000 chorych na raka piersi leczono tego typu techniką poza protokołami badań klinicznych. Wytyczne te powstały na bazie obserwacji wyników prospektywnych badań APBI z minimalnym okresem obserwacji 4 lat oraz licznych badań klinicznych i patologicznych dotyczących leczenia oszczędzającego gruczołu piersiowego. Zbiorcze zestawienie wytycznych obu organizacji przedstawia tabela I. Grupa Low risk/Suitable dla częściowego napromieniania gruczołu piersiowego wg wytycznych ASTRO/GEC-ESTRO jest dosyć restrykcyjna. Znacznie mniej wymagające wytyczne rekomenduje na przykład American Society of Breast Surgeons czy American Brachytherapy Society. Podobnie mniej restrykcyjne są kryteria włączenia do największego obecnie badania klinicznego nad APBI, czyli NSABP B-39/RTOG 0413 [8-10].

\section{Komórki nowotworowe - histopatologia}

Badania porównujące chirurgiczne leczenie $z$ radioterapią lub bez radioterapii całego gruczołu piersiowego dowodzą, iż w obu grupach wznowy miejscowe występują najczęściej w rejonie bezpośrednio sąsiadującym z lożą po wyciętym guzie. Rozkład procentowy wynosi $67-85 \%$. Napromienianie całego gruczołu piersiowego opiera się natomiast na podstawach naukowych wynikających z badań preparatów po mastektomii, w których u 43\% chorych znajdowano komórki nowotworowe w odległości ponad $2 \mathrm{~cm}$ od guza pierwotnego [11]. Gurdal i wsp. przedstawili wyniki, w których stwierdzono obecność komórek nowotworowych w preparatach dociętych lub mastektomijnych tkanek u chorych, u których wykonywano ponowny

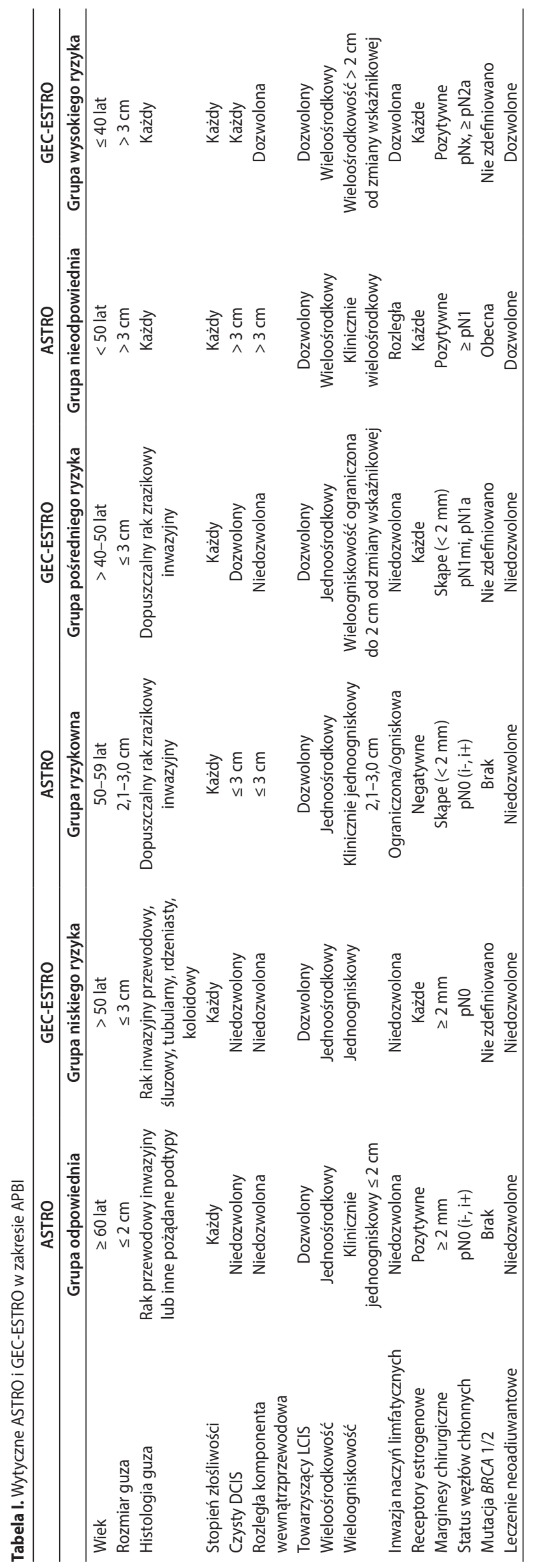


zabieg operacyjny w związku z brakiem odpowiedniego marginesu po wycięciu guza pierwotnego piersi [12]. Kolejne badania przeprowadzone w zakresie histopatologii udowodniły, iż obecność komórek raka poza ogniskiem pierwotnym jest ściśle zależna od określonych cech, morfologicznych guza pierwotnego. W pierwszym rzędzie należy tutaj wymienić obecność takich cech, jak: wielkość guza pierwotnego, stopień złośliwości, obecność i rozległość komponenty wewnątrzprzewodowej, typ zrazikowy raka, stan węzłów chłonnych i wiek chorego. Badania ostatnich lat wskazują, iż ogniska komórek nowotworowych występują głównie w odległości 1-2 cm od guza pierwotnego - występowanie w dalszej odległości należy uznać za stosukowo rzadkie [13-16]. Zgodne by to było zatem z przedstawionymi powyżej danymi odnośnie lokalizacji występowania wznów miejscowych.

Bardzo ważną publikacją dla idei APBI jest doniesienie Schmitz i wsp. z 2010 roku. Publikacja omawia korelację wyników MRI zmiany w piersi z wynikami badań histopatologicznych. Badacze w 83\% przypadków znaleźli subkliniczne ogniska raka poza guzem. Co niesłychanie istotne, dokładnie oceniono odległość od guza ognisk subklinicznych. Występowały one w $79 \% \geq 5 \mathrm{~mm}, 52 \% \geq 10 \mathrm{~mm}$, $36 \% \geq 15 \mathrm{~mm}, 20 \% \geq 20 \mathrm{~mm}, 13 \% \geq 25 \mathrm{~mm}, 7 \% \geq 30 \mathrm{~mm}$. Natomiast, analizując dalej kolejne parametry guza pierwotnego, stwierdzono, iż w przypadku braku komponenty wewnątrzprzewodowej ogniska subkliniczne nie występowały powyżej $30 \mathrm{~mm}$ od granic guza pierwotnego. Powyższe badanie udowodniło też dużą wartość i korelację wyników rezonansu magnetycznego z ostatecznym badaniem histopatologicznym preparatów pooperacyjnych [17]. Stanowi to ważny wniosek i podstawę do selekcji grup chorych kwalifikowanych do APBI.

\section{APBI - dostępne techniki}

Częściowe napromienianie gruczołu piersiowego może być realizowane na kilka sposobów, zależnie od zastosowanej techniki. Należy tutaj zwrócić uwagę, iż zdecydowana większość wyników z dłuższymi okresami obserwacji pochodzi z badań, w których stosowano śródtkankową brachyterapię na bazie tych wyników między innymi powstały rekomendacje ASTRO i GEC-ESTRO [7, 11, 13].

Śródtkankowa brachyterapia to technika najstarsza i najbardziej przebadana. Obecnie przy użyciu tej metody można zainstalować do 20 prowadnic. Instalację prowadzi się śródoperacyjnie. W przypadku techniki HDR najczęściej stosowany schemat polega na podaniu 34 Gy w 10 frakcjach dwa razy dziennie (cała procedura trwa 5 dni). Podkreśla się tutaj problem kosztów używanego sprzętu oraz potrzebę dużego doświadczenia ze strony osoby wykonującej procedurę. Z uwagi na znaczną heterogenność dawki problemem może być zwiększona częstość martwicy tłuszczowej oraz toksyczność w zakresie skóry [7, 13].
Brachyterapia balonowa (Mammosite, Axxent, Contura, Savi) jest techniką, która powstała w celu uproszczenia i rozszerzenia dostępu do brachyterapii. Podobnie jak w brachyterapii tkankowej najczęściej stosuje się dawkę 34 Gy w 10 frakcjach 2 razy dziennie. Ograniczeniem dla tej techniki jest mała wielkość gruczołu piersiowego, mniejsza niż 7 mm odległość balona od skóry, lokalizacja zmiany w kwadrancie górnym wewnętrznym [7, 13].

Radioterapia śródoperacyjna (IORT) (Intrabeam, Liac, Novac-11, Mobetron) polega na podaniu jednej frakcji napromieniania w trakcie zabiegu operacyjnego. Pod tym względem jest to technika najbardziej komfortowa zarówno dla lekarza jak i pacjenta. Urządzenie Intrabeam to aparat kilowoltażowy posługujący się niską energią fotonów. Podaje się tutaj dawkę 20 Gy w czasie 20-45 minut. Krytyka tego aparatu dotyczy problemu znacznego spadku dawki już w odległości $1 \mathrm{~cm}$ od powierzchni aplikatora. Urządzenia (Liac, Mobetron, Novac-11) to akceleratory liniowe wytwarzające wiązkę elektronów w zakresie energii 3-10 MeV. W przypadku APBI podaje się tutaj dawkę 21 Gy na lożę po guzie oraz margines 1,5-3 cm. Minusem technik śródoperacyjnych jest potrzeba zakupu specjalnego sprzętu, przystosowania sali operacyjnej oraz duże doświadczenie personelu. Podkreślanym też przez niektórych dużym minusem jest brak ostatecznego badania histopatologicznego w zakresie marginesów w momencie wykonywania procedury. Wielkim natomiast plusem APBI z użyciem radioterapii śródoperacyjnej jest możliwość stosowania technik onkoplastycznych tak szeroko obecnie adaptowanych do BCT $[7,13]$.

Radioterapia z pól zewnętrznych (3D-Conformal) możliwa jest do wykorzystania przy pomocy nowej generacji akceleratorów liniowych. Najczęściej obecnie stosowany schemat to 38,5 Gy w 10 frakcjach 2 razy dziennie (leczenie trwa 5 dni) $[7,13]$.

Trzeba zwrócić uwagę, iż pomimo trwających stale w zakresie APBI badań (technikami powyżej przedstawionymi) pojawiają się już nowe metody o zupełnie nieznanym działaniu, np. stałe radioaktywne implanty czy techniki ablacyjne prądem wysokiej częstotliwości (RFA) [7, 13].

Przedstawiając głos na tak w dyskusji na temat APBI, duży problem dotyczy właśnie powyżej przedstawionych technik. Dlaczego? Odpowiedź jest bardzo prosta: każda z metod ma swoje ograniczenia, reprezentuje zupełnie różne możliwości i charakteryzuje się odmiennymi parametrami fizycznymi i radiobiologicznymi. Co za tym idzie — trudno przedstawione techniki porównywać, a wytyczne ASTRO i GEC-ESTRO nie rozróżniają metody, jaką przeprowadzamy APBI. Zatem krytyka APBI ze strony części środowiska naukowego nie jest uzasadniona, skoro wiedza opierana jest w większości na wynikach brachyterapii śródtkankowej. Dyskusję na temat toczących się badań podejmę jednak w osobnym podrozdziale tej publikacji. Tutaj kluczowe wydaje się zwrócenie uwagi na publikację Nairza O. i wsp., 
Tabela II. APBI — badania kliniczne III fazy

\begin{tabular}{|c|c|c|c|c|c|}
\hline Trial & $\mathrm{N}$ & Kryteria włączenia & Grupa kontrolna & Grupa badana & $\begin{array}{l}\text { Data } \\
\text { rozpoczęcia }\end{array}$ \\
\hline $\begin{array}{l}\text { NSABP B-39/ } \\
\text { /RTOG } 0413\end{array}$ & 4300 & $\begin{array}{c}\text { Wiek }>18 \text { lat, stopień } \\
\text { zaawansowania I-III } \\
(T<3 \mathrm{~cm}), \text { DCIS lub rak } \\
\text { inwazyjny, } \leq 3 \text { dodatnie } \\
\text { węzły chłonne, } \\
\text { ujemne marginesy }\end{array}$ & $\begin{array}{c}\text { WBRT } \\
50 \text { Gy w } 25-28 \text { frakcjach }+ \\
\text { boost }\end{array}$ & $\begin{array}{c}\text { Brachyterapia lub MammoSite } \\
34 \text { Gy w } 10 \text { frakcjach lub 3D EBRT } \\
38,5 \text { Gy w } 10 \text { frakcjach w ciągu } \\
\text { 5-10 dni }\end{array}$ & 2005 \\
\hline $\begin{array}{l}\text { RAPID/Ontario } \\
\text { Clinical Oncology } \\
\text { Group }\end{array}$ & 2128 & $\begin{array}{c}\text { Wiek }>40 \text { lat, } \mathrm{T}<3 \mathrm{~cm} \text {, } \\
\text { DCIS lub rak inwazyjny, } \\
\text { ujemne węzły, ujemne marginesy } \\
\text { pacjentka } B R C A 1,2 \text { - ujemna }\end{array}$ & $\begin{array}{c}\text { WBRT } \\
\text { 42,5 Gy w } 16 \text { frakcjach dla } \\
\text { małych piersi lub } \\
50 \text { Gy w } 25 \text { frakcjach dla } \\
\text { większych piersi + boost }\end{array}$ & $\begin{array}{c}\text { 3D EBRT } \\
38,5 \text { Gy w } 10 \text { frakcjach w ciągu } \\
5-8 \text { dni }\end{array}$ & 2006 \\
\hline GEC-ESTRO & 1233 & $\begin{array}{l}\text { Wiek > } 40 \text { lat, Stopień } \\
\text { zaawansowania } \\
\text { 0-II (T } 3 \mathrm{~cm}), \text { DCIS lub } \\
\text { rak inwazyjny, } \\
\text { ujemne węzły lub } \\
\text { z mikroprzerzutami, } \\
\text { marginesy } \geq 2 \mathrm{~mm}\end{array}$ & $\begin{array}{c}\text { WBRT } \\
50 \text { Gy w } 25-28 \text { frakcjach + } \\
\text { boost }\end{array}$ & $\begin{array}{c}\text { Brachyterapia } \\
32 \text { Gy w } 8 \text { frakcjach HDR, } \\
30 \text { Gy w } 7 \text { frakcjach HDR, } \\
50 \text { Gy PDR }\end{array}$ & 2004-2009 \\
\hline IMPORT LOW & 1935 & $\begin{array}{l}\text { Wiek }>50 \text { lat, } \mathrm{T}<3 \mathrm{~cm}, \\
\text { Rak inwazyjny (bez zrazikowego), } \\
\text { ujemne węzły, marginesy }>2 \mathrm{~mm}\end{array}$ & $\begin{array}{c}\text { WBRT } \\
40 \text { Gy w } 15 \text { frakcjach } \\
\text { przez } 21 \text { dni }\end{array}$ & $\begin{array}{c}\text { EBRT (IMRT) } \\
\text { ramię 1: } 40 \text { Gy w } 15 \text { frakcjach } \\
\text { na lożę po guzie i } 36 \text { Gy } \\
\text { w } 15 \text { frakcjach na pozostałą pierś, } \\
\text { ramię 2: } 40 \text { Gy w } 15 \text { frakcjach na } \\
\text { lożę po guzie }\end{array}$ & 2007-2010 \\
\hline \multirow[t]{2}{*}{ ELIOT } & 1306 & Wiek $>48$ lat, $\mathrm{T} \leq 2,5 \mathrm{~cm}$ & WBRT & IORT & 2000-2007 \\
\hline & & rak inwazyjny, ujemne węzły & $\begin{array}{c}50 \mathrm{~Gy} \\
\text { w } 25 \text { frakcjach + boost }\end{array}$ & $\begin{array}{l}21 \text { Gy w } 1 \text { frakcji } \\
\text { elektronowej do } 9 \mathrm{MeV}\end{array}$ & \\
\hline IRMA & 3302 & $\begin{array}{l}\text { Wiek }>49 \text { lat, } T<3 \mathrm{~cm}, \\
\text { rak inwazyjny, } 3 \leq \text { dodatnie } \\
\text { węzły, marginesy } \geq 2 \mathrm{~mm}\end{array}$ & $\begin{array}{c}\text { WBRT } \\
45 \text { Gy w } 18 \text { frakcjach lub } \\
50 \text { Gy w } 25-28 \text { frakcjach }\end{array}$ & $\begin{array}{c}\text { 3D EBRT } \\
38,5 \text { Gy w } 10 \text { frakcjach } \\
\text { przez } 5 \text { dni }\end{array}$ & 2007 \\
\hline SHARE & 2796 & $\begin{array}{c}\text { Wiek }>50 \text { lat, } T \leq 2 \mathrm{~cm} \text {, rak inwazyjny, } \\
\text { ujemne węzły, marginesy }>2 \mathrm{~mm}\end{array}$ & $\begin{array}{c}\text { WBRT } \\
\text { ramię 1: 40-42,5 Gy } \\
\text { w15-16 frakcjach, } \\
\text { ramię 2: } 50 \text { Gy + 16 Gy } \\
\text { boost w } 33 \text { frakcjach }\end{array}$ & $\begin{array}{c}\text { 3D EBRT } \\
40 \text { Gy w } 10 \text { frakcjach } \\
\text { przez } 5-7 \text { dni }\end{array}$ & 2010 \\
\hline
\end{tabular}

którzy porównują pod kątem parametrów dozymetrycznych dostępne techniki stosowane do częściowego napromieniania gruczołu piersiowego. Okazuje się na przykład, że tzw. index niehomogenności dawki (Dose-Inhomogeneity-Index), średnia wartość odchylenia przepisanej dawki promieniowania, bardzo różni się od metod stosowanych w APBI. Na przykład wskaźnik ten wynosi: dla Mammosite 0,2952 ; dla Intrabeam 0,5887; dla brachyterapii śródtkankowej 0,6485 (5 prowadnic), 0,8935 (3 prowadnice), 1,5809 (2 prowadnice); dla radioterapii śródoperacyjnej z użyciem elektronów 0,0475 [18].

Teoretycznie wydaje się, że techniki śródoperacyjne mogą mieć przewagę nad innymi stosowanym w APBI. Nie jest to jednak udowodnione. Brak jest publikacji porównawczej na ten temat i pewnie takiej nie będzie. Wnioski takie pojawiają się w niektórych publikacjach na podstawie dowodów pośrednich. Radioterapia śródoperacyjna podawana na lożę po usuniętym guzie jako jedyna umożliwia pełną wizualizację tkanek bezpośrednio sąsiadujących z guzem pierwotnym. W ten sposób ryzyko geograficznego prze- sunięcia, spotykane w innych technikach radioterapii, jest tutaj minimalizowane.

\section{APBI - badania III fazy}

Definitywne wnioski na temat wyników leczenia APBI powinniśmy czerpać z badań randomizowanych i zgodnie z EBM jest to oczywiste. Na dzień dzisiejszy opublikowano zaledwie 4 badania 3. fazy i jedną metaanalizę w tym zakresie. Trzy z powyższych badań mają niestety znaczne ograniczenia. Badanie Yorkshire Breast Cancer Group nie zrekrutowało zakładanej liczby chorych (problemy z rekrutacją), a przy tym stosowano tutaj różne techniki w zakresie APBI [19]. W badaniu Christie Hospital zrandomizowano natomiast 708 chorych, ale główny problem to heterogenność grupy chorych. Włączono tutaj wielu chorych z niekorzystnymi czynnikami rokowniczymi [20]. Ciekawe badanie węgierskie porównujące APBI techniką brachyterapii z napromienianiem całego gruczołu piersiowego zrekrutowało małą grupę 258 chorych. Niemniej w okresie 66 miesięcy obserwacji ilość wznów miejscowych nie różniła się po- 
między badanym grupami [21]. Metaanaliza opublikowana w 2010 roku wskazuje na zwiększoną ilość wznów miejscowych i regionalnych w grupie APBI, przy braku wpływu na przeżycia całkowite [22].

Pierwszym prospektywnym badaniem randomizowanym o poziomie wiarygodności A opublikowanym na temat APBI jest badanie TARGIT. Do badania włączono 2232 chorych, porównując napromienianie całego gruczołu piersiowego z radioterapią śródoperacyjną przy pomocy aparatu Intrabeam (20 Gy 50 kV). Częstość wznów miejscowych obserwowanych w okresie 4 lat nie różniła się pomiędzy analizowanymi grupami [23, 24].

Obecnie czekamy na wyniki 7 randomizowanych badań 3. fazy (tab. II). Trzy z powyższych badań zakończyły randomizację chorych. Wyniki z okresem obserwacji powyżej 5 lat nie będą znane jednak do około 2017 roku.

APBI to ważna technika, otwierająca wiele nowych możliwości. Daje szanse na zwiększenie grupy chorych leczonych z oszczędzeniem gruczołu piersiowego. Skraca czas leczenia, co ważne jest zarówno dla chorego, jak i dla ośrodka prowadzącego leczenie. Oczywiście obecne wytyczne ASTRO i GEC-ESTRO nie są idealne, ale w pewnym stopniu regulują zasady dla APBI, pokazując grupy chorych, którzy do takiego postępowania absolutnie się nie nadają. Na wyniki toczących się ważnych badań w powyższym zakresie musimy poczekać jeszcze 5-8 lat, ale należy się spodziewać, iż odpowiedzą one przynajmniej na kilka ze stawianych obecnie pytań.

Dr hab. n. med. Dawid Murawa

IOddział Chirurgii Onkologicznej i Ogólnej

Wielkopolskie Centrum Onkologii

ul. Garbary 15, 61-866 Poznań

e-mail:dmurawa@gmail.com

\section{Piśmiennictwo}

1. Apantaku LM. Breast-conserving surgery for breast cancer. Am Fam Physician 2002; 66: 2271-2278.

2. Benda RK, Mendenhall NP, Lind DS i wsp. Breast-conserving therapy (BCT) for early-stage breast cancer. J Surg Oncol 2004; 85: 14-27.

3. Jeziorski A, Piekarski J, Towpik E i wsp. Rak piersi. W: Jeziorski A, Szawłowski AW, Towpik E. Chirurgia onkologiczna. Tom 3. Warszawa: PZWL; 2009, 811-915

4. Clark RM, Whelan T, Levine M i wsp. Randomized clinical trial of breast irradiation following lumpectomy and axillary dissection for node-negative breast cancer: an update. Ontario Clinical Oncology Group. J Nat I Cancer Inst 1996; 88: 1659-1664.

5. Antonini $\mathrm{N}$, Jones $\mathrm{H}$, Horiot JC i wsp. Effect of age and radiation dose on local control after breast conserving treatment: EORTC trial 2288110882. Radiother Oncol 2007; 82: 265-271.

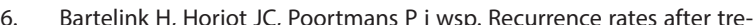
atment of breast cancer with standard radiotherapy with or without additional radiation. NEng/ J Med 2001; 345: 1378-1387.

7. Njeh CF, Saunders MW, Langton CM. Accelerated partial breast irradiation (APBI): a review of available techniques. Radiat Oncol 2010; 5: 90.

8. Smith BD, Arthur DW, Buchholz TA i wsp. Accelerated patrial breast irradiation consensus statement from the American Society for Radiation Oncology (ASTRO). Int J Radiat Oncol Biol Phys 2009; 74: 987-1001.

9. Shaitelman SF, Vicini FA, Beitsch P i wsp. Five-year outcome of patients classified using the American Society for Radiation Oncology consensus statement guidelines for the application of accelerated partial breast irradiation [...]. Cancer 2010; 116: 4677-85.

10. Polgar C, Van Limbergen E, Potteer R i wsp. Patient selection for accelerated partial breast irradiation (APBI) after breast-conserving surgery: recommendations of the Groupe Européen de Curiethérapie-European Society for Therapeutic Radiology and Oncology (GEC-ESTRO) breast cancer working group based on clinical evidence (2009). Radiother Oncol 2010; 94:264-73.

11. Antonucci JV, Wallace M, Goldstein NS i wsp. Differences in patterns of failure in patients treated with accelerated partial breast irradiation versus whole-breast irradiation: a matched-pair analysis with 10-year follow up. Int J Radiat Oncol Biol Phys 2009; 74: 447-452.

12. Gujral DM, Sumo G, Owen JR i wsp. Ipsilateral breast tumor relapse : local recurrence versus new primary tumor and the effect of whole-breast radiotherapy on the rate of new primaries. Int J Radiat Oncol Biol Phys 2011; 79; 19-25.

13. Moser EC, Vrieling C. Accelerated partial breast irradiation: the need for well-defined patient selection criteria, improved volume definition, close follow up and discussion of salvage treatment. Breast 2012; 21: 707-715.

14. Goldstein SN. Controversies in pathology in early stage breast cancer. Semin Radiat Oncol 2011; 21: 20-25.

15. Vicini FA, Kestin LK, Goldstein NS i wsp. Defining the clinical target volume for patients with early-stage breast cancer [...]: a pathologic analysis. Int J Radiat Oncol Biol Phys 2004; 60: 722-730.

16. Vin-Hung V, Verschraegen C. Breast-conserving surgery with or without radiotherapy: pooled-analysis for risks of ipsilateral breast tumor recurrence and mortality. J Nat/ Cancer Inst 2004; 96: 115-121.

17. Schmitz AC, van den Bosch MA, Loo CE i wsp. Precise correlation between MRI and histopathology - exploring treatment margins for MRI-guided localized breast cancer therapy. Radiother Oncol 2010; 97: 225-232.

18. Nairz O, Deutschmann H, Kopp M i wsp. A dosimetric comparison of IORT techniques in limited-stage breast cancer. Strahlenther Onkol 2006; 182: 342-348.

19. Dodwell DJ, Dyker K, Brown J i wsp. A randomized study of whole-breast vs tumor-bed irradiation after local excision and axillary dissection for early breast cancer. Clin Oncol 2005; 17: 618-622.

20. Ribeiro GG, Magge B, Swindell R i wsp. The Christie Hospital breast conservation trial: an update at 8 years from inception. Clin Oncol 1993; 5: 278-283.

21. Polgar C, Fodor J, Major T i wsp. Breast-conserving treatment with partial or whole breast irradiation for low risk invasive breast cancer -5 year results of a randomized trial. Int J Radiat Oncol Biol Phys 2007; 69: 694-702.

22. Valachis A, Mauri D, Polyzos NP i wsp. Patial breast irradiation or whole breast radiotherapy for early breast cancer : a metaanalysis of ranomized controlled trials. Breast J 2010; 16: 245-251.

23. Vaidya JS, Joseph DJ, Tobias JS i wsp. Targeted intraoperative radiotherapy versus whole breast radiotherapy for breast cancer (TARGIT-A trial): an international, prospective, randomised, non-inferiority phase 3 trial. Lancet 2010; 376: 91-102

24. Vaidya JS, Baum M, Tobias JS i wsp. Long-term results of targeted intraoperative radiotherapy (Targit) boost during breast-conserving surgery. Int J Radiat Oncol Biol Phys 2011; 81: 1091-1097. 